\title{
A RELAÇÃO CORPO-NATUREZA NA \\ MODERNIDADE ${ }^{1}$
}

\author{
Dulce Suassuna* \\ Jônatas Barros** \\ Aldo Azevedo ${ }^{* * * *}$ \\ Juarez Sampaio****
}

\begin{abstract}
Resumo: O trabalho apresenta uma reflexão teórica sobre o significado da relação corpo-natureza tomando como contexto a modernidade. O debate teórico proposto subsidia-se na teoria social, seguindo como referencial o pensamento weberiano no que concerne à sua visão sobre a modernidade. Ampara-se em Habermas para mostrar que na modernidade o quadro configurado se constrói por meio de rupturas que se processam como consequiências patológicas do mundo natural, momento em que se permite discutir a relação homem (corpo) e meio ambiente (natureza). A recuperação da contribuição de Habermas ocorreu por meio do texto clássico Teoria da Ação Comunicativa e da leitura de Goldblatt no seu livro Teoria Social e Ambiente. Além desses autores, outros são utilizados dentro dessa linha de pensamento, entretanto, pretendendo-se fugir da visão instrumentalista, buscou-se em Mauss, por meio da teoria do fato social total e da noção de técnicas corporais, um esforço teórico para uma possível justificativa da perspectiva da interdisciplinaridade entre o campo disciplinar das Ciências Sociais e a Educação Física e, por conseguinte, do desporto.
\end{abstract}

Palavras-chave: corpo, natureza, modernidade.

\footnotetext{
* Professora da FEF/UnB. Doutora em Sociologia.

** Professor da FEF/UnB. Doutor em Educação Física.

*** Professor da FEF/UnB. Doutor em Sociologia.

**** Professor da SEDF/UnB. Especialista em Educação Física.
}

Artigo recebido em 3 set. 2004; aprovado em 29 mar. 2005. 


\section{Introdução}

A modernidade ocidental, revestida de uma crescente racionalização instrumental de controle da natureza, cindiu o homem em corpo e espírito, assegurando-lhe concretude ao físico/corpóreo. Essa cisão significou o desenlace simbólico de valores agregados ao homem por meio do inexplicável. Buscou-se, portanto, tudo explicar por meio do pragmatismo e, até certo ponto, do ceticismo. Entretanto, o controle sobre a natureza na verdade significou o seu descontrole, isto é, aperfeiçoaram-se métodos e técnicas no acelerado processo de industrialização, mas tal instrumental não possibilitou ao homem a compreensão de sua relação consigo mesmo e com a natureza.

O presente trabalho pretende construir uma reflexão teórica sobre o significado da relação corpo-natureza tomando como contexto a modernidade. A modernidade é entendida como produtora de um discurso instrumental que tem como centro o dualismo (corponatureza) e, por conseguinte, a razão instrumental. O debate teórico proposto subsidia-se na teoria social, seguindo como referencial teórico o pensamento weberiano no que concerne à sua visão sobre a modernidade. Ampara-se em Habermas para mostrar que, na modernidade, o quadro configurado se constrói por meio de rupturas, que se processam como conseqüências patológicas do mundo natural, momento em que se permite discutir a relação homem (corpo) e meio ambiente (natureza). A recuperação da contribuição de Habermas (1987) ocorreu por meio do texto clássico Teoria da Ação Comunicativa e da leitura de Goldblatt (1996), no seu livro Teoria Social e Ambiente. Além desses dois autores, outros são utilizados dentro dessa linha de pensamento, entretanto, pretendendose fugir da visão instrumentalista do discurso moderno, buscou-se amparo na teoria do fato social total de Mauss (1974, 2003), que é vista como um esforço teórico para uma possível justificativa da perspectiva de interdisciplinaridade entre os campos das Ciências Sociais e da Educação Física. Ainda dentro de uma perspectiva antropológica, recorreu-se a Le Breton (2003) procurando situar sua preocupação sobre a noção de corpo assumida pelo projeto moderno, inserida no debate entre as ciências médicas (da saúde), as tecnologias e as ciências sociais. 
Diante deste esforço de interdisciplinaridade entre Ciências Sociais e Educação Física, propõe-se o estudo dos esportes de aventura como tema que permite o encontro entre corpo-natureza. Neste sentido, recuperam-se, por meio de Ferrando et al. (2002), alguns argumentos de Machado (1971). Tais argumentos defendem a idéia de que a atividade física na natureza, realizada desde a infância, pode permitir ao homem não só um maior conhecimento sobre a natureza, mas, também, sobre si mesmo (entendendo o homem como ser integrante da natureza).

\section{O discurso moderno: a natureza sob controle}

A modernidade representa o cenário que propaga o discurso por meio do qual os vínculos que sustentavam a relação corpo e natureza sofreram uma cisão. Com isto sugere-se que, no quadro moderno, houve um redimensionamento da relação homem-natureza. Com efeito, enquanto a natureza está atrelada à noção de espiritual e, por essa razão, tal noção foi, de certo modo, discutida apenas na transversalidade dos embates sociológicos travados entre pensadores sociais clássicos do século XIX, o corpo, que passa a ser visto durante o período moderno como algo profano, é o substrato de todas as reflexões científicas desde o século XVIII mais precisamente, considerado o Século das Luzes.

No pano de fundo da reflexão encontra-se a busca incessante do homem pelo controle da natureza, buscando aperfeiçoar técnicas e máquinas com a finalidade de promover o desenvolvimento. $\mathrm{O}$ controle sobre a natureza apresentava como elemento basilar a razão instrumental, que se sustentou por meio da cisão entre corpo e espírito. A cisão tornou-se possível com fundamento no desmantelamento da estrutura feudal e, por conseguinte, com a desestruturação do poder da Igreja Católica, proporcionando uma reorientação na concepção de homem. Conforme Le Breton (2003) desde o século XVI, mais precisamente 1543 , com a publicação do De humani corpori fabrica, houve um momento de mudança na forma de pensar o homem e sua relação com o corpo, diz o autor: "Os anatomistas antes de 
Descartes e da filosofia mecanicista fundam um dualismo que é central na modernidade e não apenas na medicina, aquele que distingue, por um lado, o homem, por outro, seu corpo" (Le Breton, 2003, p. 18).

Por meio da interpretação do autor, percebe-se que o projeto moderno teve seu matiz alinhavado na forma sistemática de encarar o homem, advinda da filosofia mecanicista e, portanto, de Descartes. Todavia, mais do que isso, a visão moderna recupera o modelo do corpo como máquina, que também é decorrente do pensamento de Descartes. Com efeito, segundo Le Breton (2003, p. 18), Descartes ao apresentar sua idéia de cogito "prolonga historicamente a dissociação implícita do homem com seu corpo despojado de valor próprio", entendendo-se com isso que o corpo é encarado como o invólucro mecânico que reveste a "essência" da natureza humana, o cogito. Por meio destas observações, percebe-se que o projeto moderno não só se fundamenta na dissociação do corpo e espírito, como também se incumbe de dividir o lado material - o corpo humano - entre essência (cogito) e aparência (corpo - parte externa).

Trata-se, portanto, de refletir o que significou essa dissecação apresentada sobre o corpo, que trouxe consigo duas referências: corpo - cogito (mente) e corpo - espírito (alma). Assim, ao se debruçar sobre essa dupla referência percebe-se que ocorreu uma resignificação do que é ser homem, que de uma forma ou de outra, implica uma visão dualista. Isto quer dizer que o projeto moderno dividiu o homem em duas partes desiguais, fazendo com que este homem, ao buscar a realização material, se situe na sociedade como um ser em busca do sentido de sua vida, na verdade, muitas vezes desacreditado ou mesmo desencantado.

A compreensão do desencantamento do homem no cenário moderno contribui para o entendimento de sua relação com a natureza, à medida que a cisão corpo-espírito se sustenta numa relação analógica entre cultural e natural. A este respeito Goldblatt (1996) permite uma incursão na teoria social, por meio de uma releitura de autores clássicos, destacando-se aqui Habermas (1987).

Para Habermas, a maneira encontrada pelo homem para lidar com os problemas gerados pela modernidade produziu quadros 
patológicos na sociedade, determinando crises de direção e, até mesmo, diminuindo a integração societária. Essas crises de direção podem ser compreendidas no sentido da teoria weberiana como o desencantamento do sujeito no quadro moderno, pois a vida para o homem aparece sem sentido em função de sua descrença, especialmente, com a vida extra-mundana (Weber, 1989). O empobrecimento cultural e a perda do significado são, conforme Habermas (1987), os dois aspectos que contribuem para a perda de referência do homem no mundo moderno. Nesta direção vale a pena atentar para o que observa Habermas (1987, p. 355, citado por Goldblatt, 1996, p. 182): “A consciência do quotidiano não é enganada, mas fragmentada. Só então se encontram reunidas as condições para pôr em prática a colonização do mundo natural". Quer dizer, então, que o fato de o homem moderno perder a referência consigo mesmo e com o lado espiritual propicia (para não dizer, determina) formas para o controle da natureza.

A singularidade do pensamento moderno consiste na definição da razão instrumental, que se ampara na busca de princípios fundamentais que devem abandonar dogmas e crenças religiosas (não-científico), enquanto os pressupostos que norteiam a ciência moderna se baseiam em um tripé que se constitui por observação, experimentação e comprovação dos fatos, estabelecendo-se leis gerais e invariáveis para todos os fenômenos "científicos", isto é, passíveis de investigação científica. Neste contexto, tanto o racionalismo (movimento intelectual surgido no século XVII) quanto o iluminismo (século XVIII) subsidiam-se nas hard sciences, talvez por convicção ou por conveniência. Portanto, negava-se tudo o que não fosse devidamente (cientificamente) comprovado, por oportuno, contrariavase o imaterial como forma de controlar a natureza e construir uma ciência a serviço do desenvolvimento da humanidade, contribuindo, assim, para a consolidação de um novo modelo de sociedade (Suassuna, 1999).

O controle sobre a natureza consistiu no grande fundamento da ciência ocidental moderna ou ciência secular. Estabelecem-se convenções que se apresentam como verdadeiras oposições (material 
e imaterial, corpo e mente, corpo e espírito, científico e não-científico, cultural e natural), justificando, com isso, a textura científica de determinadas disciplinas. Vê-se, por assim dizer, que tais categorias de pensamento são utilizadas de modo dual, maneira encontrada para mostrar sua oposição discursiva. Desta forma, como efetivamente o rural era o espaço e o cenário do feudo, do crente, da Religião institucionalizada (católica), pretende-se, na modernidade, fugir dele como forma de superá-lo. Aqui, pode-se construir uma associação entre o que representa o rural e o natural, posto que é exatamente o que ocorre no cenário moderno. Nega-se a concepção de natural, associando-a ao modelo de dominação medieval em que prevalecia o meio rural, isto é, o Feudalismo (Weber, 1989).

Na dinâmica desse processo, o capitalismo, a demografia, a política, a urbanidade e o industrialismo aparecem como elementos que dimensionam um modelo de sociedade pautado em um mecanismo complexo e conflituoso, que se embasa em causas diretas, motivadoras da degradação ambiental de per si, e, causas estruturais, correlacionadas aos fatores históricos e estruturais da degradação ambiental (Habermas, 1987).

As categorias corpo e natureza são apresentadas sob uma tensão, o que sugere não apenas a existência de uma dualidade, mas emerge a ponto de assumir um caráter de conflito. Corpo significando o material, e natureza sendo reportada a algo que está além do corpóreo, portanto, está relacionada ao imaterial, voltando-se, mais uma vez à relação natural-cultural. Trata-se, como afirma Goldblatt (1996), de uma questão ontológica que se cristaliza por meio do paradoxo estabelecido entre sujeito humano e objeto natural. Com isso, pode-se inferir que a natureza é tratada como algo mítico, intocável, coisas de outro plano, plano este superior ao corpóreo. Que razões justificariam tomar a natureza como algo extra-mundano? Como atribuir significado à relação corpo e natureza numa sociedade em que todas as categorias parecem esvaziadas de sentido? Tais questões aparecem no pano de fundo do dualismo construído pelo projeto moderno e que serviu como matiz para alargar o abismo entre o sujeito (corpo) e o meio ambiente, mundo natural, como chama Habermas (1987) ou, natureza, seguindo Merleau-Ponty (2000). 
A categoria natureza recebeu como herança da teoria social clássica, principalmente dos escritos de Durkheim, Marx e Weber preocupações transversais (Goldblatt, 1996), isto é, estes autores não se preocuparam com as conseqüências do capitalismo sobre o meio ambiente. Suas análises se encaminharam dentro das seguintes preocupações centrais: no caso de Durkheim (1995), para a constituição de um modelo de sociedade complexa - solidariedade orgânica - que se originou da especialização das profissões em razão da divisão do trabalho social; para Marx (1989), a questão principal era a análise do funcionamento da sociedade capitalista; e, por fim, no caso de Weber (1989) o ponto norteador de sua interpretação era a compreensão da constituição ética do capitalismo. Com efeito, que fatores poderiam justificar a pouca preocupação dos cientistas sociais com a questão do controle do homem sobre a natureza?

Segundo Rodrigues (1983, p. 14), "pela natureza do seu espírito, o homem não pode lidar com o caos. Seu medo maior é o de defrontarse com aquilo que não pode controlar, seja por meios técnicos, seja por meios simbólicos". Retoma-se a questão: não é a natureza uma categoria ainda fora de controle para o homem? Em função disso, é mais fácil relegá-la a uma outra dimensão do que propriamente lidar com ela. Por essa razão, o homem deu conta do processo de industrialização, das técnicas, da produção, mas não construiu categorias analíticas suficientemente capazes de explicar sua relação com a natureza.

A necessidade de explicar a relação corpo-natureza está centrada no bojo de uma discussão sobre o que fazer com a natureza. Será que é necessário destruí-la, já que não podemos controlá-la? De acordo com Goldblatt (1996), existem dois motivos de diferentes ordens que promovem a devastação ambiental, quais sejam: as interações diretas, como, por exemplo, um índio derrubar uma árvore para fazer lenha e as pressões históricas e estruturais, que consistem na determinação de motivações sociais, como subemprego, desemprego, escassez de capital, que podem compelir um agricultor a devastar o ambiente. Neste último caso, a visão do homem sobre a natureza aparece como fundamento que acaba por instrumentalizar 
a relação homem-natureza, percebendo o homem como não-integrante da natureza.

Merleau-Ponty, por seu turno, consegue fugir dessa percepção ao afirmar que:

Existe natureza por toda parte onde há uma vida que tem um sentido, porém, não existe pensamento; daí o parentesco com o vegetal: é natureza o que tem um sentido, sem que esse sentido tenha sido estabelecido pelo pensamento. É a auto-produção de um sentido. A Natureza é diferente, portanto, de uma simples coisa; ela tem um interior, determina-se de dentro; daí a oposição de 'natural' e 'acidental'. (Merleau-Ponty, 2000, p. 4).

Fica-se, pois, com a idéia de que natureza é a auto-produção de um sentido. Esse sentido é aqui interpretado como a intenção dos atores sociais, portanto, não se consegue escapar da interpretação recorrente no pensamento weberiano de que as condutas humanas, inclusive em relação à natureza, sejam racionais. Como pensa Husserl "a Natureza envolve tudo, a minha percepção e a dos outros, enquanto estas só podem ser para mim um afastamento do meu mundo" (citado por Merleau-Ponty, 2000, p. 19).

Concorda-se, portanto, com a idéia de natureza trazida por Husserl (a partir de Merleau-Ponty, 2000), o que permite a aproximação com a noção dos sujeitos como indivíduos capazes de exprimir sentidos (percepções) por meio de suas condutas. Naquela interpretação, a natureza é expressa como uma construção social, pois como afirmou o autor, natureza é tudo que não é individual. Isto é, natureza é tudo aquilo que permite a localização do sujeito - corpo - no mundo (social).

\section{O corpo e seu significado}

Caracterizado na modernidade por meio de aspectos biológicos, o corpo é parte do conteúdo estudado por uma ciência secularizada que assume os pressupostos do dualismo cartesiano, em especial 
disciplinas como Biologia, Medicina, Fisioterapia e Educação Física, que tradicionalmente o assumem como objeto de estudo. Para a visão predominante no campo disciplinar que as envolve, o corpo é definido como uma célula autônoma ou por várias células funcionando de modo integrado, sugerindo-se com isso a harmonia entre órgãos no desempenho de suas funções. Entretanto, por si só, essa definição que se registre, é adotada pelo funcionalismo, especialmente, por Durkheim (1995) ao fazer analogia entre o corpo humano e o corpo social - apresenta-se como insuficiente, isto é, é limitada porque ao definir-se o corpo de modo biológico, como o foi, chega-se a um lugar comum, pois tanto pode se expressar pela definição o corpo de um animal qualquer ou o de um ser humano.

A visão remanescente do determinismo biológico teve lugar durante o século XIX também nas Ciências Sociais em função do pensamento evolucionista. Todavia, ao longo da discussão acumulada sobre o assunto percebeu-se que uma definição meramente biológica, que considere a dimensão humana sob apenas um aspecto não pode servir como referência para os estudos sobre o corpo que envolvam o indivíduo de modo integral. Neste âmbito, Mauss (2003) ao apresentar sua noção de técnica corporal consegue situar o diálogo entre diferentes campos disciplinares, especialmente o das Ciências Sociais e o da Educação Física - que, tradicionalmente, está inserida no campo das Ciências da Saúde.

Para Mauss (2003, p. 401) são técnicas corporais "as maneiras pelas quais os homens de sociedade em sociedade, de uma forma tradicional, sabem servir-se de seus corpos". Ao apresentar sua noção de técnica corporal, o autor recorta o corpo como objeto de preocupação da Etnologia e amplia sua contribuição ao passo que considera o homem como um ser total, isto é, na constituição humana, os aspectos biológicos, psicológicos e sociais se fazem presentes. Com isso, Mauss (2003) conseguiu promover uma ruptura com a visão preponderante no campo das Ciências da Saúde e também no das Ciências Sociais. Por meio dela, esse autor rompeu com o determinismo biológico, mas também com vertentes sociológicas que pretendiam, durante o século XIX, tratar o homem apenas sob o 
prisma social. Por esta razão, concordando-se com Mauss (1974, 2003), compreender a dimensão humana é partir do pressuposto de que o homem constitui um fato social total. Lévi-Strauss, na introdução de Sociologia e Antropologia de Mauss (1974), destaca que, desde 1926, Mauss defendeu que para interpretar a relação indivíduosociedade era necessário relacionar imediatamente o fisiológico e o social.

Desta forma, enquanto autores racionalistas discutiam a noção conflituosa entre corpo e espírito ou corpo e mente, debate que remonta ao dualismo cartesiano, para que dissecações e olhares que os tornam objetos pudessem ser suportados e, que resultou na mecanização da lógica corpórea, com o conseqüente desencantamento do corpo, fragmentando-o, Mauss (1974) permanece à frente e propõe o estudo das técnicas corporais como objeto da pesquisa etnológica. Com efeito, Mauss (1974) considerava indispensável para uma disciplina que se preocupa com o estudo da cultura (construída por homens), que a Etnologia realizasse o inventário de tudo que os homens fazem dos seus corpos, ou seja, de todos os usos e apropriações do homem sobre seu corpo ao longo da história. E critica dizendo que continuamos a ignorar inúmeras possibilidades do corpo humano, tudo isso porque nos preocupamos com fragmentos ou com visões instrumentais sobre esse corpo.

Conforme Rodrigues (1999), a visão que desencadeia a fragmentação do corpo, impedindo, inclusive, que ele seja visto como parte da natureza, foi a consequiência de um processo não meramente casual, pois, o período histórico coincide com a consolidação da sociedade capitalista, pretendendo-se, naquele momento, transformar os corpos em instrumentos funcionais, espécie de máquinas. É válido ressaltar que neste caso, em particular, as idéias de Rodrigues (1999) e Le Breton (2003) são convergentes e apresentam pontos de ligação ao mostrar que o corpo serve ao processo produtivo de modo sincrônico $^{2}$ e mecânico, tal qual uma peça na engrenagem de um motor. Como se observa por meio da passagem abaixo:

[Na modernidade] a vida passará a adquirir sentido mediante contraposições e dicotomias: entre o mundo do natural e o do 
sobrenatural, entre o do subjetivo e o do objetivo, entre o da realidade e o da imaginação, entre o do verdadeiro e o do falso, entre o da sociedade e o do indivíduo, entre o da natureza e o da cultura. Aquele amálgama, aquela integridade do universo medieval serão contínuos e cada vez mais profundamente fracionados, para dar lugar à lógica de segregações que doravante atribuirá sentido ao mundo, ditará os princípios que vão presidir as mentalidades e sensibilidades posteriores e que deverão resultar na nossa ciência, na nossa etiqueta, nosso meio ambiente, nossa resistência, nossa postura corporal... (Rodrigues, 1999, p. 63).

Deste modo, passaram a ter lugar as dicotomias, fragmentações, que se revestem em categorias que se pautam em uma crescente racionalização instrumental de controle da natureza.

Para reforçar sua interpretação acerca da noção dual como parte do projeto moderno, Rodrigues (1999) recorre a fatos históricos da Idade Média, mostrando que, por meio deles, é possível perceber que o sentido das categorias corpo e espírito eram bem diferentes dos tempos modernos, como se observa a seguir:

Um dos aspectos mais característicos e de mais difícil entendimento para a mentalidade contemporânea é que espírito e matéria não se opunham. Não se imaginava, nos tempos medievais, que os seres humanos possuíssem, por um lado, um espírito - indestrutível, transcendente e sublime - que se contrapusesse, por outro, a uma matéria fadada à degradação e à decomposição, por ser portadora de dignidade menor. A corporalidade medieval era valorizada em si, até porque continha o que hoje chamamos de espiritual. (Rodrigues, 1999, p. 55).

Vê-se, pois, que a difícil compreensão do significado da mentalidade medieval na modernidade tem como um dos aspectos o fato de que o homem era compreendido dentro de um modelo baseado no dualismo cartesiano, isto é, enquanto espírito e matéria em separado. Com efeito, o projeto moderno "jogou o bebê fora com a água do banho", isto é, foi responsável pela construção de rupturas no homem, que passou a ser redimensionado como corpo e espírito 
separadamente, o que quer dizer que o homem avançou significativamente em relação ao aperfeiçoamento técnico, à industrialização, mas, por outro lado, esqueceu de buscar a redescoberta de si mesmo como sujeito autor da história e como ser natural e cultural que é. Então, o projeto moderno estruturou, por meio do seu discurso, uma visão fragmentária do homem, entendido apenas sob o prisma corpóreo. Diante deste cenário, quais seriam as possibilidades concretas de permitir que o homem vislumbre um contato próximo com a natureza e, desta maneira, possa romper com a separação proposta pelo racionalismo entre corpo/cultura e natureza/ imaterial?

Como mostram Ferrando et al. (2002) tanto o processo industrial como as atuais condições dos centros urbanos começam a promover uma espécie de sentimento/necessidade no homem de buscar práticas de atividades físicas na natureza. As razões dessa busca são enunciadas pelos autores com base na urbanização e na tecnificação da sociedade moderna. Contudo, acrescentam que é necessário se pensar nos impactos causados pelas práticas dessas atividades na natureza, porém, com base nas argumentações de Machado (1971), defendem que o contato desde a infância com a natureza, permite que a atividade física encontre uma base real para o desenvolvimento da cultura corporal, fugindo de exercícios mecanizados e, muitas vezes, descontextualizados da "natureza" humana. Observa o autor:

Para crear hábitos saludables, que nos acompañen saludables, que nos acompañen toda la vida, no hay peor camino que el de la gimnasia y de los deportes, que son ejercicios mecanizados, en cierto sentido abstractos, desintegrados tanto de la vida animal como de la ciudadana. (...) Si lográsemos, en cambio, despertar en el niño el amor a la naturaleza, que se deleita en contemplarla, o la curiosidad por ella, que se empeña en preservarla y conocerla, tendríamos mas tarde hombres maduros y ancianos venerables, capaces de atravesar la sierra de Guadarrama e los días más crudos del inverno, ya por deseo de recrearse en el espectáculo de los pinos y de los montes, ya movidos por el afán científico de estudiar de lagartijas... (Machado, 1971, p. 97 citado por Ferrando et al, 2002, p. 193). 
De acordo com as considerações do autor, pode-se perceber que a contextualização da atividade física na natureza pode despertar nas crianças a vontade de aprender mais sobre a natureza, estimulando o processo cognitivo e até mesmo a redefinição da relação entre corpo-natureza. Este aspecto pode ser capaz de re-significar um modelo educativo que tome como premissa a necessidade do conhecimento do homem sobre a natureza, percebendo-o como dela integrante e, deste modo, promovendo o elo entre corpo-espírito ou corpo-mente. Assim, o contato com a natureza pode permitir a compreensão de que o homem é parte intrínseca da natureza e não algo dissociado e perdido.

\section{Considerações finais}

Neste ensaio buscou-se promover um diálogo entre autores com o propósito de discutir a temática da modernidade e a relação corpo e natureza, procurando-se enfatizar a contribuição teórica da teoria social para o campo da Educação Física. Neste sentido, além de se ter como objetivo promover um debate com autores que sustentam a teoria social, mostrando suas limitações em relação à problemática escolhida - relação corpo-natureza -, procurou-se, principalmente, construir uma fundamentação teórica para iniciar a discussão com base no pensamento social clássico e, desta maneira, redimensionar o debate entre o campo das Ciências Sociais e o da Educação Física.

Mostrou-se, por meio da Teoria Social, que a modernidade, sustentada por meio de um discurso instrumental do desenvolvimento e da racionalidade técnica, cindiu o homem em corpo-espírito, negando a sua face espiritual, tendo em vista que esta se distanciava dos interesses racionais da sociedade capitalista.

Viu-se, por outro lado, que é possível apresentar uma crítica ao discurso instrumental do projeto moderno por meio de Mauss, à medida que este autor utiliza o conceito de fato social total (diga-se de passagem, que é recorrente nos estudos de vieses antropológicos). 
Considerou-se que a leitura de Mauss, inclusive, coincidindo com a reedição de sua obra Sociologia e Antropologia, até então esgotada no Brasil, permitiu a fuga ao dualismo cartesiano. Retomando-se a discussão proposta sobre a natureza, Mauss permitiu que o discurso instrumental sobre ela seja superado, e, ao mesmo tempo, possibilitou que o homem seja pensado dentro de uma tríade (biológica, psicológica e social) - fato social total - que por muito tempo foi refutada pelas Ciências Modernas (neste caso, tanto as naturais, quanto as sociais).

Por meio deste ensaio, tornou-se perceptível que o objetivo entender a relação corpo-natureza, situando o homem no contexto da modernidade -, pressupondo-se que este homem moderno, ao fugir de práticas cotidianas consideradas rotineiras, busca no contato com a natureza a si mesmo e ao elo perdido com o mundo natural no contexto da modernidade, pode ter um significado importante para a compreensão do homem no sentido ontológico do termo. Deste modo, considerando a Antropologia como uma disciplina à procura de significados e o homem como o sujeito que está buscando o sentido de sua vida, sendo, portanto, o papel da Antropologia a compreensão/ interpretação do sentido atribuído pelo homem (Oliveira, 1997), defendeu-se que é fundamental o diálogo entre campos disciplinares distintos, mas que registram preocupações comuns. Esse diálogo deve ser recorrente e, desta forma, pode contribuir para a ampliação do exercício de reflexão sobre o tema.

Por fim, se o homem moderno está à procura do bebê jogado fora com a água do banho - bebê que representou o sentido de sua vida, isto é, a referência perdida no contexto moderno com o abandono do lado espiritual - ele pode ser encontrado à medida que a interação/ relação homem-natureza é restabelecida, tendo na atividade física na natureza (para nós, esportes de aventura) uma possibilidade real para promover este encontro. 


\section{Notas}

1 Trata-se de um trabalho teórico que é parte de um projeto de pesquisa que começou a ser desenvolvido no ano de 2002, pelo Núcleo de Estudos do Corpo e Natureza (Necon FEF/UnB), em que se investiga o significado da relação Corpo e Natureza, por meio do estudo dos esportes de aventura. Colaboraram na discussão Daniel Cantanhede, Davi Metaxa, Paulo Aires (bolsistas voluntários) e Lucimar Neves Schelgshorn (bolsista PIBIC/CNPq). Este trabalho foi apresentado no VIII Congresso Luso-Afro-Brasileiro “A questão social no novo milênio", realizado em Coimbra, Portugal, em setembro de 2004. Foi financiado pela Capes e Finatec.

2 Sincronizar quer dizer ajustar com rigorosa precisão. Tal categoria também é trabalhada por Durkheim (1995), ao explicar a função do indivíduo na sociedade, relação que é caracterizada por meio da vinculação entre parte e todo, respectivamente.

\section{Abstract: The body-nature relation in the Modernity}

This paper presents a theoretical reflection about the meaning of the body-nature relation, taking Modernity as a context. The theoretical discussion proposed here is subsidized by the social theory, following the weberian thinking as a reference, where it concerns the view of Modernity. It uses Habermas to show that in modernity the shaped picture is built by means of breaches which occur as pathological consequences of the natural world; moment in which the man (body)environment (nature) relation can be discussed. The recovery of the contribution of Habernas happened through the classic text Theory of the Communicative Action and the reading of Goldblatt in his book Social and Environment Theory. Besides these authors, others are used within this line of thought. However, attempting to dodge the instrumentalist view, Mauss was embraced as a basis, through the theory of the total social fact and the notion of body techniques, in order to find theoretical support for a possible justification of the perspective of interdisciplinary studies between the field of Social Sciences and Physical Education and, consequently, of the sport.

Key-words: body, nature, modernity. 


\section{Referências bibliográficas}

DURKHEIM, Émile. Da divisão do trabalho social. São Paulo: Martins Fontes, 1995.

FERRANDO, Gárcia; BARATA, Núria Puig; OTERO, Francisco Lagardera (Comps.) Sociologia del deporte. 2. ed. Madri: Alianza, 2002.

GOLDBLATT, David. Teoria social e ambiente. Lisboa: Instituto Piaget, 1996.

HABERMAS, Jürger. The theory of commuicative action. Boston.: Polity Press, 1987. v. 2.

LE BRETON, David. Adeus ao corpo: Antropologia e sociedade. Campinas: Papirus, 2003.

MACHADO, A. Juan de Mairena: sentencias, donaires, apuntes y recuerdos de um profesor apócrifo 1936. Edición de José María Valverde. Madri: Editorial Castalia, 1971.

MARX, Karl. O Capital. Tradução de Reginaldo Sant'Anna. 13. ed. São Paulo: Bertrand, 1989. Livro I e I.

MAUSS, Marcel. Sociologia e Antropologia. São Paulo: E.P.U., 1974. . Sociologia e Antropologia. São Paulo: Casac \& Naify, 2003.

MEARLEAU-PONTY, Maurice. A Natureza. São Paulo: Pioneira, 2000.

OLIVEIRA, Roberto Cardoso de. O trabalho do antropólogo. Brasília: Paralelo 15, 1997.

RODRIGUES, José Carlos. O tabu do corpo. 3. ed. Rio de Janeiro: Achiamé, 1983.

Antropologia e saúde. Rio de Janeiro: Fiocruz, 1999.

SUASSUNA, Dulce. Do objetivismo à intersubjetividade: o lugar da razão na modernidade. Revista Brasiliense de Pós-Graduação em Ciências Sociais - Pós, Departamento de Antropologia e Centro de Pesquisa de Pós-Graduação sobre a América Latina e Caribe, UnB, Brasília, Edição temática, v. 3, n. 1. 1997.

WEBER, Max. A ética protestante e o espírito do capitalismo. São Paulo: Pioneira, 1989. 